\title{
DEVELOPMENT OF A STATISTICS CALCULATOR FOR DESCRIPTIVE ANALYSIS OF DATABASE
}

\author{
Michele Ferraz Figueiró, Patricia M. M. Chicon and Leo N. Paschoal \\ Universidade de Cruz Alta, Brazil \\ Centro de Ciências da Saúde e Agrárias, Brazil \\ mfigueiro@unicruz.edu.br
}

The advancement of technologies of information and communication has motivated the development of the most different and innovative manners of propagating knowledge through the Web. The teaching-learning process must be designed in such a way as to allow a perfect integration between technological tools and learning actions used in education.

In this work, we have developed a statistics calculator for webpage with the purpose of performing the descriptive analysis of database. The web programming language used to develop this calculator was PHP together with other web languages, such as HTML, CSS and JavaScript. This web application is going to be an important tool to help both our undergraduate and graduate students as professors in their statistics lectures or in the data analysis of their research projects.

The descriptive analysis is the initial part of the data analysis used to describe, organize and summarize the collected data (Larson \& Farber, 2003). Before performing the descriptive analysis is necessary to classify variables as qualitative and quantitative. In our case, we are interested in calculating the measures of location and the measures of dispersion of the quantitative variables. The measures of location calculated are minimum, maximum, mode, mean, and percentiles. The measures of dispersion calculated are range, interquartile range, variance, standard deviation and coefficient of variation.

In the main window page of the statistics calculator, the sequence of data should be typed manually or imported from a text file (txt extension). Therefore, it is possible that the web application calculates the measures of position and the measure of dispersion of this database. These results are displayed in html format and the print of this content can be also requested.

A test of the white-box type (Pressman, 2010) was done to validate the source code of the web application in order to evaluate its internal structures and to repair some found semantic errors.

\section{REFERENCES}

Larson, R. \& Farber, B. (2003). Elementary Statistics (3rd edition). Ney Jersey: Prentice Hall. Pressman, S. R. (2010). Software Engineering (7th edition). New York: McGraw-Hill. 